\title{
Anatomical and functional outcomes of one year of intravitreal ranibizumab and aflibercept injections: Real- life data
}

\author{
Irfan Perente ${ }^{1}$, Alev Kockar ${ }^{2}$, Ozgur Artunay ${ }^{1}$ and Elvan Alper Sengul ${ }^{2 *}$ \\ ${ }^{1}$ Beyoglu Training and Research Hospital Ophthalmology Department, Istanbul \\ ${ }^{2}$ T.C. Istanbul Bilim University Medical Faculty Ophthalmology Department, Istanbul
}

\begin{abstract}
Purpose: This study aimed to compare the functional and anatomical outcomes of intravitreal ranibizumab (IVR) and intravitreal aflibercept (IVA) injections in patients with neovascular age-related macular degeneration (AMD).

Methods: The medical records of 80 AMD patients who received IVR treatment and IVA treatment were assessed. During each visit, best corrected visual acuity (BCVA) and central macular thickness (CMT) were measured. IVR and IVA were administered once per month for three consecutive months, and injections were repeated monthly, as needed, for 1 year.
\end{abstract}

Results: No significant differences were detected between the two groups at baseline and 12-month measurements; CMT decreased by $74.95 \mu \mathrm{m}$ in IVR group and $74.06 \mu \mathrm{m}$ in IVA group ( $\mathrm{p}>0.05$ ). In addition, BCVAs in both groups demonstrated an increase of 5.93 letters compared to the baseline ( $>>0.05$ ).

Conclusion: After 1 year, there were no significant differences between groups, in BCVA, CMT, and number of injections with as-needed regimen.

\section{Introduction}

Neovascular age-related macular degeneration (AMD) is the most common cause of severe vision loss at a later age [1]. Angiogenesis plays a critical role in those diseases that frequently lead to blindness, such as diabetic retinopathy, retinopathy of prematurity, and age-related macular degeneration [2]. Vascular endothelial growth factor (VEGF), which has strong mitogenic effects on endothelial cells and increases vascular permeability, may stimulate angiogenesis when it is released from cells in hypoxic and ischemic conditions [3]. Overall, VEGF is the main angiogenesis inducer in the formation of neovascularization in AMD and diabetic retinopathy $[4,5]$. The treatment of AMD involves the suppression of VEGF, which plays a crucial role in pathogenesis of AMD [6-8].

Blocking all isoforms of AMD, ranibizumab, a recombinant humanized monoclonal fragment antigen binding (Fab) to human VEGF, was approved by the Food and Drug Administration (FDA) in June of 2006 [9]. Previous randomized controlled studies conducted with intravitreal ranibizumab (IVR) have revealed that a monthly injection results in the highest rate of visual acuity gain [10,11]. A similar improvement in visual acuity was obtained with pro re nata (PRN) administration in the Prospective Optical Coherence Tomography Imaging of Patients with Intraocular Ranibizumab (PrONTO) study, which was decided to repeat the injection according to the results of visual acuity and optical coherence tomography (OCT) after an initial three-month loading dose period [12].

Intravitreal aflibercept (IVA) was approved for use by the FDA in November of 2011. A bi-monthly IVA injection, after a loading dose of 3 monthly injections, was determined to be non-inferior when compared to the IVR injections at the end of 12 months. In the next year, the same study continued with varying dose regimens, and both medications were found to be equally effective in terms of the visual acuity $[13,14]$. In addition, there are several studies that included switching to IVA for those patients with no or a partial response to the IVR treatment [15-17].

Based on the above information, the present study aimed to compare the real-life data of the one-year application of these two intravitreal agents, which are widely used in clinical practice.

\section{Methods}

This study incorporated a retrospective assessment of the records of 40 eyes of 40 consecutive patients who were given IVR, and 40 eyes of 40 consecutive patients who were given IVA at the ophthalmology department of Istanbul Bilim University. They were all diagnosed with nAMD and followed up for 1 year on an as-needed basis at our clinic from March 2015 to December 2016. The study was approved by the Ethics Committee of Istanbul Bilim University. Written informed consent was obtained from each subject with the ethical principles stated in the "Declaration of Helsinki".

Correspondence to: Elvan Alper Sengul, Abidei Hurriyet cad. Sisli Florence Nightingale Hastanesi Goz Hastaliklari Klinigi Sisli/Istanbul, Tel: 00905326371900; E-mail: ealper_sengul@yahoo.com

Key words: age related macular degeneration, anti-VEGF therapy, central macular thickness, intravitreal aflibercept, intravitreal ranibizumab

Received: March 01, 2018; Accepted: March 13, 2018; Published: March 25, 2018 
Inclusion was set as meeting all of the following criteria: a best corrected visual acuity (BCVA), as measured by the Early Treatment Diabetic Retinopathy Study (ETDRS) scale, ranging between 20/40 and 20/200; the existence of leakage demonstrative of choroidal neovascularization (CNV) or macular edema according to fundus fluorescein angiography (FFA); the presence of subretinal fluid, cystic maculopathy, or a central macular thickness (CMT) of at least $250 \mu \mathrm{m}$, as detected by OCT (Optovue, Fremont, USA); having never been treated for macular degeneration and followed-up for at least 1 year. Exclusion was set as meeting at least one of the following criteria: the existence of any disease (other than AMD) that might reduce visual acuity; vitrectomy having been applied to the subject eye; received retinal photocoagulation treatment until 1 month prior to the onset of the study; missed at least one control visit; aphakia or the posterior capsule not being solid; the existence of glaucoma; or the presence of chronic renal failure and bleeding diathesis.

The IVR (Lucentis; Novartis Pharma AG, Basel, Switzerland) at a dose of $0.5 \mathrm{mg} / 0.05 \mathrm{ml}$ and IVA (Eylea; Bayer Pharma, Berlin, Germany) at a dose of $2 \mathrm{mg} / 0.05 \mathrm{ml}$ were injected once per month for three consecutive months. The decision about whether to keep up further injections was made on an as-needed basis. During each visit, the best corrected visual acuity (BCVA) was measured by means of the ETDRS scale. Each visit also incorporated a biomicroscopic examination of the anterior segment, measurement of the intraocular pressure, a fundus examination, and a CMT measurement via OCT. For all of the patients, the diagnosis of nAMD was confirmed by indocyanine green (ICG) angiography. Any repeated injections were decided in light of the BCVA and CMT results for a given patient. The following criteria were sought while making a decision about reinjection: persistence or recurrence of subretinal fluid or cystic structures via OCT, an increase in the latest CMT by $100 \mu \mathrm{m}$ or more, as measured by OCT, incipient $\mathrm{CNV}$, incipient hemorrhage, and a loss of 5 or more letters when compared to the last recorded BCVA.

The intraocular injections were carried out under operating theater conditions. Following the topically applied proparacaine, the eyelids, lashes, and conjunctiva were cleaned with $5 \%$ povidone iodine. After the placement of the speculum to keep the eyelids open, IVR and IVA were injected at a distance of $4 \mathrm{~mm}$ from the superior temporal quadrant. After the injection, the patient was given a topical antibiotic in the quinolone group to use 4 times each day for a period of 7 days.

Adverse events (AEs), serious AEs, and changes in vital signs were assessed during all visits. Biochemical values were measured at first visit and after 12 months, and hematology, blood chemistry, and urine were regularly monitored. Intraocular pressure measurement (before and after each administration by tonometry) and standard ophthalmic examination were also performed at every visit.

\section{Statistical Analysis}

When evaluating the findings obtained in this research, SPSS 22.0 software was used for the statistical analysis. The mean \pm standard deviation (SD) and median (interquartile range, IQR) were rendered when assessing the study findings. The Kolmogorov-Smirnov test was employed to analyze the distributional behaviors of the measured data. A chi-squared test was used to analyze the differences between the IVR and IVA injections, while a t test was used to analyze the independent samples. The differences between the baseline and 12-month measurements were analyzed using the Wilcoxon signed-rank test. The results were considered within a confidence interval of $95 \%$ and a significance level of $\mathrm{p}<0.05$.

\section{Results}

The average ages of the 40 patients in the IVR group and the 40 patients in the IVA group were $73.280 \pm 5.368$ years old and $74.920 \pm$ 4.953 years old, respectively ( $\mathrm{p}>0.05$ ). The baseline CMTs in the IVR and IVA groups were $365.450 \pm 69.282 \mu \mathrm{m}$ and $363.180 \pm 58.017 \mu \mathrm{m}$, respectively $(\mathrm{p}>0.05)$. There was no statistically significant difference between the IVR and IVA groups in terms of the baseline BCVA (54.150 \pm 6.258 letters and $54.230 \pm 5.877$ letters, respectively; $\mathrm{p}>0.05$ ). The patients' demographic details are summarized in Table 1.

The average number of injections in the IVR and IVA groups over the course of the 12-month period was 7.38 and 7.35, respectively. However, no statistically significant difference was found between these two groups in terms of the number of injections ( $>>0.05)$ (Figure 1 and 2).

The 12-month CMT measurement in the IVR group revealed a decrease of $74.95 \mu \mathrm{m}$ when compared to the baseline measurements, whereas a decrease of $74.06 \mu \mathrm{m}$ was determined in the IVA group; these were statistically significant for both groups $(p<0.05)$. However, there was no significant difference between the groups in terms of the baseline and 12-month CMT measurements ( $\mathrm{p}>0.05)$ (Figure 3).

An improvement of 5.93 letters was detected in the 12-month BCVA in the IVR group when compared to the baseline measurement, with the IVA group reflecting the exact same results. These BCVA

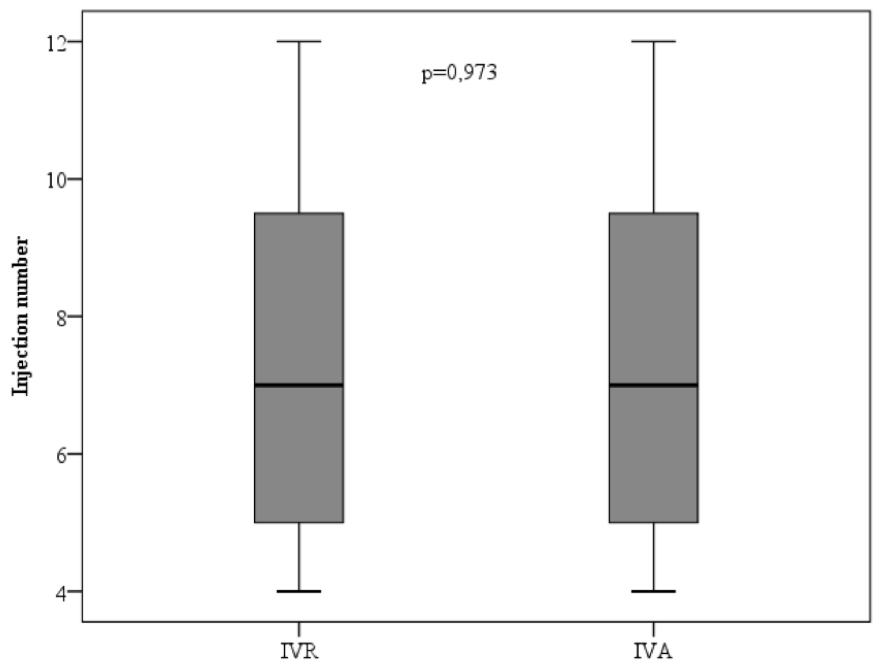

Figure 1. Comparison of mean injection numbers of intravitreal ranibizumab (IVR) and intravitreal aflibercept (IVA) groups at one year.

Table 1. The patients' demographic details.

\begin{tabular}{|c|c|c|c|}
\hline & IVR & IVA & \\
\hline$(n=40)$ & $(n=40)$ & & \\
\hline Sex & Female & $22(\% 55,0)$ & $21(\% 52,5)$ \\
\hline Male & $18(\% 45,0)$ & $19(\% 47,5)$ & \\
\hline Age & Mean \pm SD & $73,280 \pm 5,368$ & $74,920 \pm 4,953$ \\
\hline Median (IQR) & $73,5(69-77,75)$ & $74(70-78,8)$ & \\
\hline HT & $17(\% 42,5)$ & $19(\% 47,5)$ & \\
\hline DM & $7(\% 17,5)$ & $7(\% 17,5)$ & \\
\hline Smoking & $18(\% 45,0)$ & $19(\% 47,5)$ & \\
\hline CMT Baseline & Mean \pm SD & $365,450 \pm 69,282$ & $363,180 \pm 58,017$ \\
\hline Median(IQR) & $366(299-424)$ & $361(318-398)$ & \\
\hline VA Baseline & Mean \pm SD & $54,150 \pm 6,258$ & $54,230 \pm 5,877$ \\
\hline Median(IQR) & $56(49-59)$ & $55(49-58)$ & \\
\hline
\end{tabular}

* Statistical analysis performed using the chi-square test

** Statistical analysis performed using the Mann-Whitney U test 
improvements in both groups were statistically significant $(\mathrm{p}=0.000)$. However, there was no significant difference between the groups in terms of the baseline and 12-month measurements of the BCVA improvement ( $\mathrm{p}>0.05$ ) (Figure 4).

Two patients (5\%) experienced sub-conjunctival hemorrhage in IVR group and three patients (7.5\%) experienced transient IOP elevation after 15 minutes from application in IVA group which were resolved without medication.

\section{Discussion}

Intravitreal ranibizumab was approved for use in the treatment of AMD by the FDA in June of 2006. Since then, many studies have been conducted to establish the optimal dose of the drug and to determine the frequency of injections required to protect vision. Once the as-needed method (which relies on determining injection repetition according to the BCVA and OCT results obtained after a three-monthly injection loading dose) revealed similar outcomes, it went into extensive use [12,18].

The VEGF Trap-Eye: Investigation of Efficacy and Safety in Wet AMD 1 and 2 studies (VIEW 1 and 2) compared monthly injections of $0.5 \mathrm{mg}$ of IVR, monthly injections of $2 \mathrm{mg}$ of IVA, and bimonthly

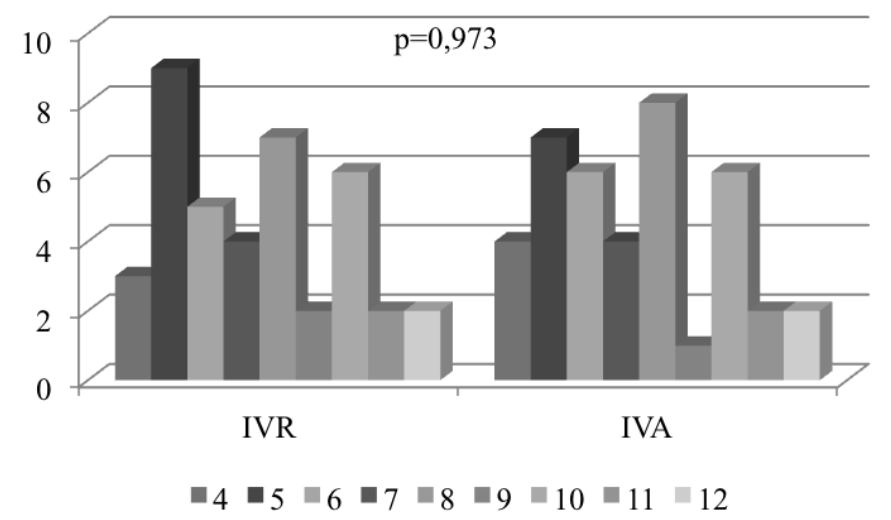

Figure 2. Distribution of injection numbers of intravitreal ranibizumab (IVR) and intravitreal aflibercept (IVA) groups.

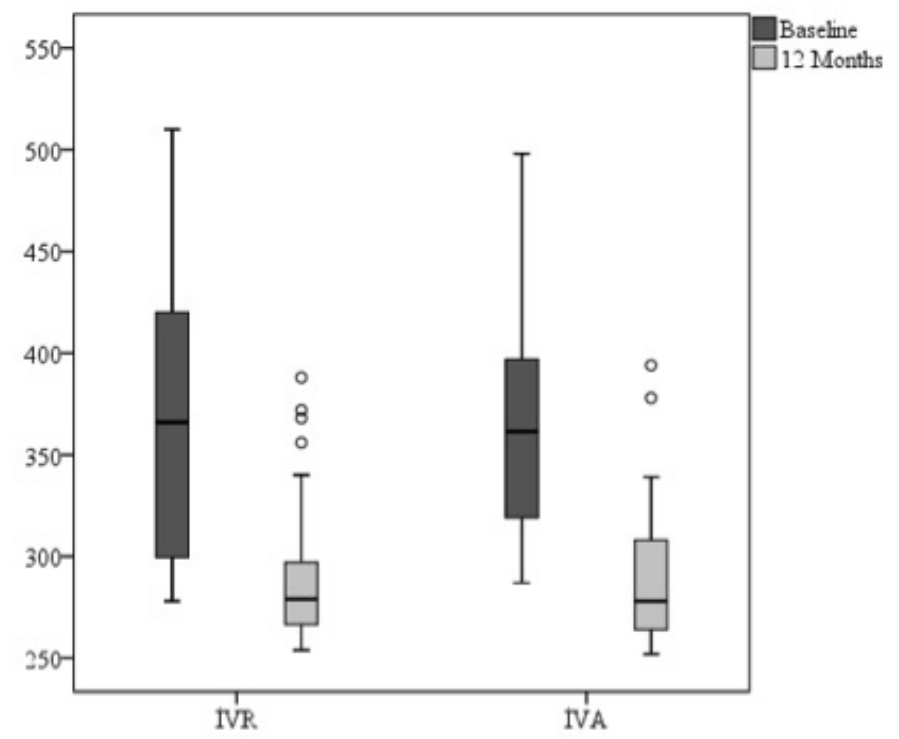

Figure 3. Changes in central macular thickness of intravitreal ranibizumab (IVR) and intravitreal aflibercept (IVA) groups at one year.

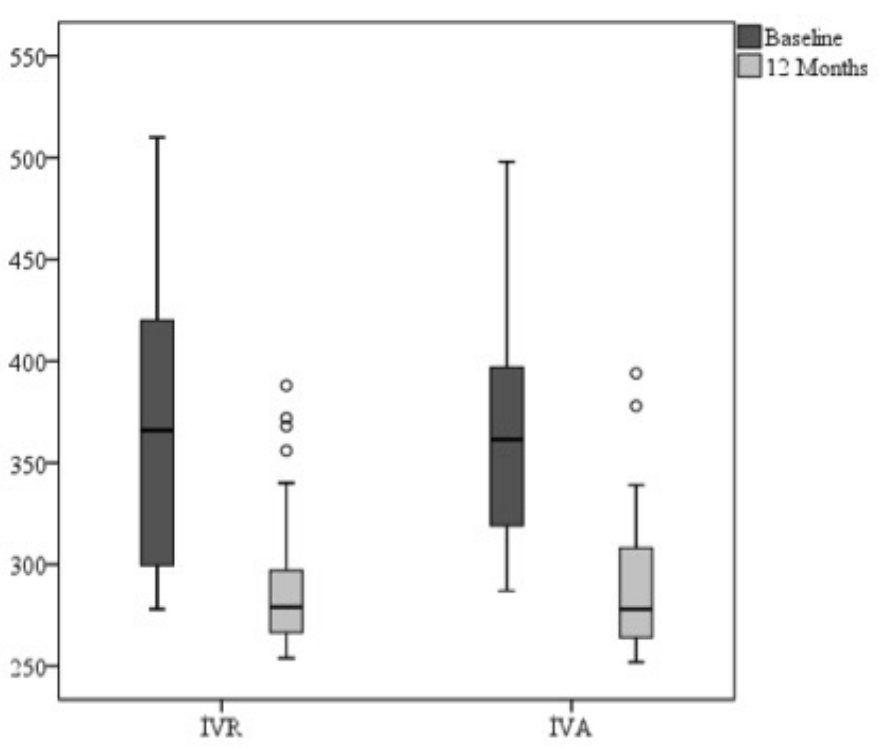

Figure 4. Changes in best corrected visual acuity (BCVA) of intravitreal ranibizumab (IVR) and intravitreal aflibercept (IVA) groups at one year.

injections of IVA, after the initial three monthly injections loading dose suggested no statistically significant difference between the 3 groups after 1 year in terms of letter gains in the scope of BCVA improvement and CMT decrease. The VIEW 1 study found letter gains in the scope of BCVA improvement of 8.1, 10.4, and 7.9 letters for the monthly IVR group, monthly IVA group, and bimonthly IVA group, respectively. The VIEW 2 study calculated the same parameter as 9.4, 7.6, and 8.9 letters, respectively. However, the decreases in the CMT were 117, 117 , and $129 \mu \mathrm{m}$ for the monthly IVR group, monthly IVA group, and bimonthly IVA group, respectively, in the VIEW 1 study. These values were 139, 157, and $149 \mu \mathrm{m}$, respectively, in the VIEW 2 study [13].

A study by Gillies et al. [19] retrospectively analyzed one-year BCVA findings pertaining to treatment-naïve patients with nAMD who were followed up under the Fight Retinal Blindness database, and who received 197 injections of IVR and 197 injections of IVA. The BCVA of the patients who received the IVR injections increased from 58.6 to 62.3 letters at the end of one year, while the BCVA of the patients who received the IVA injections increased from 58.9 to 63.1 letters $(p>0.05)$. The annual averages of the injections were 8.1 and 8.0 in the IVR and IVA groups, respectively ( $p>0.05)$. The number of visits was 9.6 and 9.5 in the IVR and IVA groups, respectively $(p>0.05)$. There was a switch to the other intravitreal agent in 27 of the patients who initially received the IVR, and in 6 of the patients who initially received the IVA $(\mathrm{p}<0.05)$. However, as-needed, treat and extend and monthly injection methods were employed at the participating centers. The treatment methods used by 17 of the participating centers remained unknown. Three of the patients included in the study had one eye in the IVR group and one in the IVA group. Moreover, the OCT findings of the patients were not evaluated.

In the present study, the letter gain was found to be 5.93 letters in both groups. Since the as-needed treatment method was used in our protocol, our patients received 13 follow up visits. We are of the opinion that following up the patients at a single center, applying injections by the same method, conducting BCVA measurements by the same specialist, and checking the CMT using the same device produce more reliable results in terms of the real-life data. The 12-month measurement of the CMT in the IVR group revealed a decrease of 74.95 
$\mu \mathrm{m}$ against the baseline measurements, whereas a decrease of $74.06 \mu \mathrm{m}$ was determined in the IVA group.

In another study that compared the IVR and IVA on the basis of asneeded treatment, after an initial three monthly injections loading dose, the baseline and final BCVAs in the IVR group were $0.86 \pm 0.45$ and $0.72 \pm 0.56$, respectively, with $0.73 \pm 0.37$ and $0.58 \pm 0.41$, respectively, in the IVA group ( $>0.05)$. The average number of injections was $4.5 \pm$ 1.3 and $4.3 \pm 0.9$ in the IVR and IVA groups, respectively. In line with the responsible physician's decision, the control visits were performed at intervals of 1 to 2 months [20]. As demonstrated by previous studies, in the case of the IVA injections, fluctuations in the CMT might be observed, albeit with BCVA improvement during the bimonthly visits $[13,21,22]$. In the present study, the average number of intravitreal injections was 7.38 and 7.35 in the IVR and IVA groups, respectively. We consider that the difference between the abovementioned study and ours in terms of the number of injections might have been caused by the irregular nature of the control visits, which led to late decisions to repeat injections.

Another study by Böhni et al. [23] was conducted on the basis of 11 patients who received IVA injections and 16 patients who received IVR injections on an as-needed basis, with a follow up period of one year. The IVA group showed an improvement of 5.63 letters, whereas an improvement of 15 letters was discovered in the IVR group at the end of the study period. However, this difference was not considered to be statistically significant. A decrease in the CMT was found (78.45 $\mu \mathrm{m}$ and $155.5 \mu \mathrm{m}$ in the IVA and IVR groups, respectively); however, this difference was not considered to be statistically significant, either. The annual average number of injections was 8.49 in the IVA group and 8.28 in the IVR group. We believe that the differences between this study and ours in terms of the letter gain and CMT decrease might have been caused by the design of the study. The two groups, as classified by Böhni et al., had differences in terms of the baseline BCVA and CMT measurements $(-10.3$ letters and $-140.36 \mu \mathrm{m}$, respectively).

The weaknesses of this study may be expressed as the relatively lower number of patients, shorter follow-up period, and its retrospective nature. In addition, the intravitreal injections were given on an as-needed basis after a three monthly injections loading dose. Thus, the patients were visited monthly, and no difference was found between the two groups in terms of the number of visits. However, the strengths of the present study include the following: every patient was visited on a monthly basis, the BCVA and OCT measurements were recorded every month, and all of the injections were implemented at a single center.

To conclude, in light of the real-life data obtained on the basis of 1-year IVR and IVA injections under an as-needed regimen, there were no significant differences between the IVR and IVA groups in terms of the BCVA, CMT, number of injections, and number of patient visits.

\section{References}

1. Bressler NM, Bressler SB, Congdon NG, Ferris FL 3rd, Friedman DS, et al. (2003) Potential public health impact of Age-Related Eye Disease Study results: AREDS report no. 11. Arch Ophthalmol 121: 1621-1624. [Crossref]

2. Jampol LM, Ebroon DA, Goldbaum MH (1994) Peripheral proliferative retinopathies: An update on angiogenesis, etiologies and management. Surv Ophthalmol 38: 519-540. [Crossref]

3. Distler O, Neidhart M, Gay RE, Gay S (2002) The molecular control of angiogenesis. Int Rev Immunol 21: 33-49. [Crossref]

4. Rezar-Dreindl S, Sacu S, Eibenberger K, Pollreisz A, Bühl W, et al. (2016) The intraocular cytokine profile and therapeutic response in persistent neovascular agerelated macular degeneration. Invest Ophthalmol Vis Sci 57: 4144-4150. [Crossref]
5. Aiello LP, Avery RL, Arrigg PG, Keyt BA, Jampel HD, et al. (1994) Vascular endothelial growth factor in ocular fluid of patients with diabetic retinopathy and other retinal disorders. $N$ Engl J Med 331: 1480-1487. [Crossref]

6. Campochiaro PA, Aiello LP, Rosenfeld PJ (2016) Anti-vascular endothelial growth factor agents in the treatment of retinal disease: from bench to bedside. Ophthalmology 123:78-88. [Crossref]

7. Rosenfeld PJ (2016) Optical coherence tomography and the development of antiangiogenic therapies in neovascular age-related macular degeneration. Invest Ophthalmol Vis Sci 57: 14-26. [Crossref]

8. Jaffe GJ, Kaiser PK, Thompson D, Gibson A, Saroj N, et al. (2016) Differential response to anti-VEGF regimens in age-related macular degeneration patients with early persistent retinal fluid. Ophthalmology 123:1856-1864. [Crossref]

9. Blick SK, Keating GM, Wagstaff AJ (2007) Ranibizumab. Drugs 67: 1199-1206. [Crossref]

10. Brown DM, Kaiser PK, Michels M, Soubrane G, Heier JS, et al. (2006) Ranibizumab versus verteporfin for neovascular age-related macular degeneration. $N$ Engl J Med 355: 1432-1444. [Crossref]

11. Rosenfeld PJ, Brown DM, Heier JS, Boyer DS, Kaiser PK, et al. (2006) Ranibizumab for neovascular age-related macular degeneration. $N$ Engl J Med 355: 1419-1431. [Crossref]

12. Lalwani GA, Rosenfeld PJ, Fung AE, Dubovy SR, Michels S, et al. (2009) A variabledosing regimen with intravitreal ranibizumab for neovascular age-related macula degeneration: year 2 of the PrONTO Study. Am J Ophthalmol 148:43-58. [Crossref]

13. Heier JS, Brown DM, Chong V, Korobelnik JF, Kaiser PK, et al. (2012) Intravitreal aflibercept (VEGF trap-eye) in wet age-related macular degeneration. Ophthalmology 119:2537-2548. [Crossref]

14. Schmidt-Erfurth U, Kaiser PK, Korobelnik JF, Brown DM, Chong V, et al. (2014) Intravitreal aflibercept injection for neovascular age-related macular degeneration: ninety-six-week results of the VIEW studies. Ophthalmology 121:193-201. [Crossref]

15. Pinheiro-Costa J, Costa JM, Beato JN, Freitas-da-Costa P, Brandão E, et al. (2015) Switch to Aflibercept in the Treatment of Neovascular AMD: One-Year Results in Clinical Practice. Ophthalmologica 233: 155-161. [Crossref]

16. Cho H, Shah CP, Weber M, Heier JS (2013) Aflibercept for exudative AMD with persistent fluid on ranibizumab and/or bevacizumab. Br J Ophthalmol 97: 1032-1035. [Crossref]

17. Kumar N, Marsiglia M, Mrejen S, Fung AT, Slakter J, et al. (2013) Visual and anatomical outcomes of intravitreal aflibercept in eyes with persistent subfoveal fluid despite previous treatments with ranibizumab in patients with neovascular age-related macular degeneration. Retina 33: 1605-1612. [Crossref]

18. Schmucker CM, Rücker G, Sommer H, Virgili G, Loke YK, et al. (2015) Treatmen as Required versus Regular Monthly Treatment in the Management of Neovascular Age-Related Macular Degeneration: A Systematic Review and Meta-Analysis. PLoS One 10: e0137866. [Crossref]

19. Gillies MC, Nguyen V, Daien V, Arnold JJ, Morlet N. (2016) Twelve-month outcomes of ranibizumab vs. aflibercept for neovascular age-related macular degeneration: data from an observational study. Ophthalmology 123: 2545-2553. [Crossref]

20. Kim JH, Lee DW, Chang YS, Kim JW, Kim CG (2016) Twelve-month outcomes of treatment using ranibizumab or aflibercept for neovascular age-related macular degeneration: a comparative study. Graefes Arch Clin Exp Ophthalmol 254: 21012109. [Crossref]

21. Schmidt-Erfurth U, Eldem B, Guymer R, Korobelnik JF, Schlingemann RO, et al (2011) Efficacy and safety of monthly versus quarterly ranibizumab treatment in neovascular age-related macular degeneration: the EXCITE study. Ophthalmology 118: 831-839. [Crossref]

22. Cohen SY, Maloberti B, Fajnkuchen F, Nghiem-Buffet S, Delahaye-Mazza C, et al (2014) Bimonthly ranibizumab for neovascular age-related macular degeneration. Ophthalmologica 231: 80-85. [Crossref]

23. Böhni SC, Bittner M, Howell JP, Bachmann LM, Faes L (2015) Comparison of Eylea $\mathbb{R}$ with Lucentis ${ }^{\circledR}$ as first-line therapy in patients with treatment-naïve neovascular agerelated macular degeneration in real-life clinical practice: retrospective case-series analysis. BMC Ophthalmol 15:109. [Crossref]

Copyright: (C)2018 Jun Z. This is an open-access article distributed under the terms of the Creative Commons Attribution License, which permits unrestricted use, distribution, and reproduction in any medium, provided the original author and source are credited. 